\title{
Correction to: Journal of Ocular Pharmacology and Therapeutics 2016;32:355-364
}

N The July/August 2016 issue of Journal of Ocular Pharmacology and Therapeutics (vol. 32, no. 6; 355-364), the article entitled "Effects of Rho Kinase Inhibitors on Intraocular Pressure and Aqueous Humor Dynamics in Nonhuman Primates and Rabbits" by Toris et al. requires a correction.

On page 364, Acknowledgments section must be added recognizing Alcon Laboratories and Research to Prevent Blindness as follows:

\section{Acknowledgments}

This work was supported by Alcon Laboratories and an unrestricted grant from Research to Prevent Blindness.

The online version of the article has been corrected to reflect this change. The authors apologize for this omission.

DOI: 10.1089/JOP.2016.0069.correx

\section{Correction to: Journal of Ocular Pharmacology and Therapeutics 2016;32:606-622}

I

N The November 2016 issue of Journal of Ocular Pharmacology and Therapeutics (vol. 32, no. 9; 606-622), the article entitled "Prostanoid Receptor Antagonist Effects on Intraocular Pressure, Supported by Ocular Biodisposition Experiments" by Woodward et al. requires a correction.

In the Acknowledgment on page 620, Allergan, Inc. and Research to Prevent Blindness must be recognized as follows:

\section{Acknowledgments}

The authors with to express their gratitude to Medicilon/MPI, Preclinical Research (Shanghai) LLC for conducting the rabbit ocular DMPK studies. This work was supported by Allergan, Inc. and an unrestricted grant from Research to Prevent Blindness.

The online version of the article has been corrected to reflect this change. The authors apologize for this omission. 